\title{
Sistematización de la comunicación institucional en medios universitarios, caso UCACUE
}

\section{Systematization of institutional communication in university media, UCACUE case}

\author{
Fabián Vladimir Argudo Palomeque ${ }^{1}$ \\ ${ }^{1}$ Universidad Católica de Cuenca \\ *vargudo@ucacue.edu.ec
}

DOI: https://doi.org/10.26871/killkana_social.v3i3.457

\begin{abstract}
Resumen
La investigación parte desde la Comunicación Organizacional como un corpus interdisciplinar que conjuga la Educación Superior y a la Universidad Católica de Cuenca (UCACUE) con la optimización y correcta utilización de sus propios medios de comunicación. Este documento dialoga con las Políticas de Comunicación Institucional. Barbero sostiene que en el continente se ha profundizado la brecha no declarativa entre la Universidad y la Sociedad, lo que obliga a todas las Instituciones de Educación Superior (IES) el repensar de lo que están haciendo. Este trabajo se enfoca en la construcción de una propuesta teórica, metodológica y práctica que ha de sustentar la comunicación institucional de medios universitarios, en el caso de la UCACUE, en sus medios: radio Ondas Cañaris, Telecuenca y medios digitales propios. Es importante el reconocer las prácticas y procesos de comunicación en medios de la Universidad, a fin de entender su alcance e influencia en la sociedad y a su vez indagar su efectividad. Esta propuesta es importante debido a que la institución se ha ubicado de manera significativa dentro del país. Por otra parte, dentro y fuera de la institución se crean procesos organizativos de información, con la finalidad de posicionar su imagen.
\end{abstract}

Palabras clave: Educación Superior, comunicación organizacional, medios universitarios, academia, vinculación.

\begin{abstract}
The research arises from the Organizational Communication as an interdisciplinary corpus that combines both, Higher Education and the Catholic University of Cuenca (UCACUE, in Spanish) with the optimization and correct usage of their own media. This document dialogues with Institutional Communication Policies. Barbero claims that the nondeclarative gap between the University and the Society has been deepened in the continent, which forces all Higher Education Institutions (HEI) to reconsider what they are doing. This work focuses on the construction of a theoretical, methodological, and practical proposal that will sustain the institutional communication of university media; in the case of UCACUE, in its media Ondas Cañaris radio, Telecuenca, and its own digital media. It is important to recognize the communication practices and processes in the UCACUE media, in order to understand their extent and influence in society, and at the same time, to inquire into their problems. This proposal is important because UCACUE is located significantly within the country. On the other hand, inside and outside the institution organizational information processes are created in order to enhance its reputation.
\end{abstract}

Keywords: Higher Education, organizational communication, university media, academy, bonding.

\section{Introducción}

Las Universidades en Ecuador y el resto del mundo cumplen un papel vital dentro de la sociedad, insertando profesionales dotados de conocimientos y comprometidos en buscar desarrollo y progreso del país.

Es necesario fortalecer un sistema de comunicación institucional dentro de la Universidad Católica de Cuenca y aplicarlo para un mejor manejo de la información y calidad en contenidos y difusión.
En un mundo globalizado y donde la comunicación en redes es de prioridad, se ve una falencia en este aspecto, ya que la comunicación e información que la entidad brinda es escasa, irrelevante o nula, haciendo que sus públicos no tengan la información suficiente, generando molestias.

El trabajo de investigación se enfocó en el estudio de los sistemas de comunicación en medios propios de la institución, es decir, el manejo de la comunicación en el nivel superior, el caso de la Universidad Católica de Cuenca; como: radio Ondas Cañaris, Telecuenca, Redes Sociales 
(Facebook, Twitter, YouTube), correo institucional, Página Web y otros medios comunicacionales, durante septiembre, octubre y noviembre de 2018

Esta investigación es importante para: reconocer las prácticas y procesos de comunicación en medios propios de la Universidad Católica de Cuenca, a fin de entender su alcance e influencia en la sociedad cuencana y a su vez indagar la efectividad de los mismos, a través de un sistema que los reglamente.

El estudio y propuesta del Sistema de Comunicación Institucional es importante debido a que la Universidad Católica de Cuenca se ha posicionado de manera significativa dentro de la ciudad, por otra parte, dentro y fuera de la institución se crean procesos organizativos de información, esto con el fin de mejorar la imagen de la casa de estudios superiores.

En el Ecuador y específicamente en Cuenca, no existen estudios acerca de un Sistema de Comunicación Institucional para universidades, lo que existe son estudios acerca de comunicación organizacional, relaciones públicas, aspectos tecnológicos, audiencias, política y leyes.

La propuesta del Sistema de Comunicación Institucional en medios de la Universidad Católica de Cuenca, está enfocada en los espacios de los medios de comunicación propios de la casa de estudios superiores, como lo son medios digitales, redes sociales, Radio Ondas Cañaris y el canal de televisión Telecuenca.

Las actividades diarias del departamento de comunicación ubicado en la matriz de la Universidad, abrirá el panorama para comprobar el uso adecuado de un sistema de comunicación institucional.

\section{Los objetivos son:}

1) Determinar cuáles son los sistemas de difusión institucional de la Universidad Católica de Cuenca

2) Evaluar si la comunicación de la Universidad Católica de Cuenca tiene los alcances y efectos requerido por sus medios de comunicación propios.

3) Conocer cuáles son los públicos que posee la Universidad Católica de Cuenca y los medios más efectivos para la difusión de información.

4) Elaborar un sistema de comunicación efectiva para los públicos de la Universidad Católica de Cuenca a través de sus medios propios.

5) Impulsar el uso adecuado para cada medio de comunicación (radio, prensa, televisión, medios digitales y redes sociales) en la Universidad Católica de Cuenca a través de un sistema de comunicación reglamentario.

Es fundamental que al ejecutar esta investigación, se aportará a más de construir la propuesta metodológica, vincular directamente la participación de docentes y estudiantes de la Carrera de Comunicación Social y Periodismo en el desarrollo, elaboración, producción y realización de productos comunicacionales para que puedan ser transmitidos en los medios institucionales de la UCACUE, hecho que hasta el momento no se ha realizado de una manera permanente a través de una política institucional de medios, es decir, entra en escena nuevamente academia, investigación y vinculación, mirando un horizonte con una política institucional.

Hipótesis o ideas a defender: La propuesta del Sistema de Comunicación Institucional de los medios de la Universidad Católica de Cuenca fortalecerá la comunicación interna y externa.

\section{Marco teórico o antecedentes}

\subsection{Políticas de comunicación}

Las políticas de comunicación en América Latina tienen sus inicios en los años 70, en donde se buscaba la democracia comunicativa, la libertad de expresión, la defensa de los derechos ciudadanos. Esto con la finalidad de hacer una comunicación más justa para todos.

Es necesario entender que las relaciones comunicación y política, tienen temas de fondo, Barbero, (2001) expone algunas ellas como: la reconstrucción de lo público, la constitución de los medios y las imágenes en espacio de reconocimiento social, las nuevas formas de existencia y ejercicio de la ciudadanía, (2001, p.70). La suma de estas premisas en la actualidad permite entender que el espacio de aplicación para las nuevas políticas es muy ancho ya que existen diversidad de culturas, identidades y comunidades dentro de un país o región.

Otro de los problemas que existe, es la falta de control a los intereses privados ya que estos no aceptan ningún medio de regulación, debido a que interfieren a sus formas abusivas de operar. Susana Seel (2010), en el artículo Políticas de Comunicación en el Capitalismo Contemporáneo, menciona que existe un monopolio global que integra horizontal y verticalmente todo el ámbito comunicacional (radio, televisión, video, cine, prensa, videojuegos, revistas, industria editorial, parques recreacionales, Internet), destaca aquí el poder de la publicidad que está al servicio del poder político tradicional (p. 21). Con todos esto, cada vez se pierde la identidad cultural local, por la fuerte entrada y difusión de contenido que viene de afuera, esto por la búsqueda principal de rentabilidad.

Uno de los objetivos de las políticas de comunicación es detener la privatización por motivos como la consolidación de pocos grupos nacionales y transnacionales. (MartínBarbero y cols., 2001, p.73). Se busca entonces que las personas puedan verse, oírse, tal cual son, con cualidades y características que los hacen únicos en su diario vivir.

Es así que la apropiación y el reconocimiento es otro fin de estas políticas, esto permiten que las distintas culturas puedan socializar, fortalecer una buena comunicación y crear identidades que los hace iguales y a la vez diferentes de los otros. La importancia del buen manejo de los medios de comunicación es vital dice Valerio Fuenzalida (2013), esto debe recaer en una empresa especializada y tener espacios públicos o canales para este fin. (Fuenzalida, 1986)

Para Martín Barbero (2001), lo más importante en las políticas de comunicación pasa por reglamentar y controlar los medios, es la lucha contra el espectáculo para confundir 
a la ciudadanía, buscando primordialmente el derecho de ser visto y oído que equivale a existir individual y colectivamente. (p.78)

En la actualidad existen muchos movimientos sociales que buscan ser visibilizados y reconocidos como mujeres, jóvenes, homosexuales entre muchos otros. Es en este punto donde las nuevas tecnologías y redes juegan un papel importante ya que permiten un desarrollo o fusión de los medios tradicionales con los digitales, creando un nuevo ecosistema comunicativo, esto a su vez permite la creación de nuevos lenguajes, sensibilidades, saberes y escrituras, destacándose entre toda la reintegración de la imagen al campo de la producción del conocimiento. (2001, p.83)

Comunicación institucional en la educación superior

Al hablar de comunicación institucional en la educación superior es necesario volver al pasado, donde la universidad tuvo sus orígenes por conflictos entre la fe y la razón. Pasó de ser conocida como Universitas (unidad de las cosas diversas) para llegar a ser conocida en la actualidad como universidad desde 1261. (Borrero-Cabal, 2008)

Los avances tecnológicos en la actualidad permiten la masificación de medios para una comunicación dentro de una institución superior, pero puede ser una trampa de doble filo dice Martín Barbero, ya que el mal uso de los mismos puede ocultar problemas internos y externos simulando modernización y bien estar. (Martín-Barbero, 1998) Por otra parte, el buen uso de las tecnologías y una buena organización multimedia puede ayudar a crear formas efectivas de interactividad y participación de todos y todas los que conforman la institución teniendo la oportunidad de ser vistos y escuchados.

El autor Carlos Tünnermann (2007), en su libro La Educación Superior en América Latina y el Caribe: diez años después de la Conferencia Mundial de 1998, presenta una lista de algunos objetivos que debe buscar la comunicación institucional en la educación superior (p.50):

El desarrollo humano, la igualdad de género, una cultura de paz, docencia, investigación, autonomía con responsabilidad social, una cultura informática, de la calidad y de la pertinencia social, identidad, visión, misión cultural de la universidad, rol protagónico de docentes y estudiantes, flexibilidad académica, diversificación, acreditación, financiamiento, deterioro ambiental, cooperación internacional, políticas públicas.

\section{Metodología}

Para cumplir con la investigación se utilizó la metodología de investigación cualitativa, se programó las siguientes actividades que lleven a comprender la problemática estudiada.

1) Localización, lectura y análisis de todas las fuentes bibliográficas posibles relacionadas con el sistema de comunicación institucional en la educación superior, puede ser en bibliotecas, como espacios digitales y otros lugares a los que se tengan acceso. Las obras tomadas en cuenta en la investigación será de los autores que gocen de credibilidad, además deberán ser de un formato científico.

Esta técnica se le denomina revisión bibliográfica, sirvió para realizar el estado de arte y posteriormente el marco teórico y conceptual.

2) Las entrevistas a profundidad fueron útiles en esta investigación. Es por eso que se localizaron fuentes primarias y con amplio conocimiento sobre comunicación institucional, medios de comunicación y medios universitarios.

3) Por último, se construyó este artículo científico, para mostrar a la colectividad acerca del sistema de comunicación institucional en la educación superior.

\subsection{Población y la muestra}

Los sujetos sociales investigados son los integrantes de la Universidad Católica de Cuenca vinculados a los medios de la universidad. Para este proceso investigativo se ejecutó un mapeo de cada receptor de medios en el contexto de la ciudad, su ubicación, el uso del espacio y la diversidad de targets.

Para proceder con el trabajo se investigó a todo el universo, puesto que luego de hacer la revisión bibliográfica, los datos obtenidos determinaron que las fuentes primarias son personas que han hecho estudios anteriores sobre el sistema de comunicación, personajes relevantes y contexto inicial.

Los Públicos y la nuestra interna es: 7 personas en Telecuenca. 8 personas en radio Ondas Cañaris. 2 personas departamento de comunicación de la Universidad Católica de Cuenca. 400 estudiantes de los últimos ciclos

El universo es la Universidad Católica de Cuenca entre funcionarios, autoridades, estudiantes y docentes. Otra parte importante para esta investigación fue contar con conocedores, profesionales que aportaron con datos múltiples, sobre el tema de relaciones públicas y administración.

\section{Resultados}

\subsection{Análisis descriptivos de los datos}

Es importante realizar un análisis de audiencia y contenidos ya que de estos depende, la eficacia de lo que la empresa quiera decir, ofertar, vender y que a su vez que los públicos tengan el impacto y alcance requerido. La utilización ya sea de medios radiofónicos y televisivos son los más frecuentes, siendo su prioridad el obtener más audiencia y con ello réditos económicos en caso de ser una entidad privada, ya que en una pública lo que se desea e imponer ideales gracias a la propaganda.

El no analizar la audiencia puede traer efectos negativos graves, ya que la empresa no sabría qué es lo que el público desea o no sea ver. Cabe indicar que son las audiencias las que publicitan en los medios de comunicación y con esto la empresa se sostiene. No solo debe preocupar lo antes mencionado, sino que la competencia está siempre vigilante. 
La televisión y los demás medios de comunicación tradicionales y digitales son los responsables de generar contenidos de calidad, contrastada, verificada y contextualizada, para que todos los públicos puedan ver, informarse, entretenerse y generar opinión.

\subsubsection{Medios tradicionales}

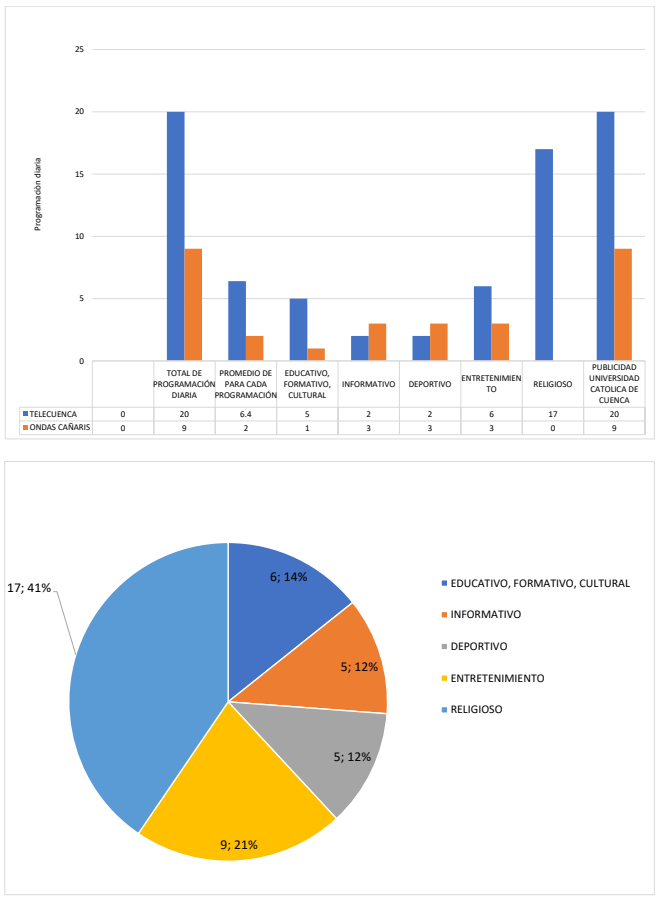

Figura 1. Tipo de Programación en medios tradicionales

De 29 programas entre radio y TV 17 con un porcentaje de $41 \%$ es religioso; 9 con un porcentaje de $21 \%$ es de entretenimiento; 6 con un porcentaje de $14 \%$ es educativo, formativo y cultural; 5 con un porcentaje de $12 \%$ es informativo y 5 con un porcentaje de $5 \%$ es deportivo.

\subsubsection{Medios digitales}

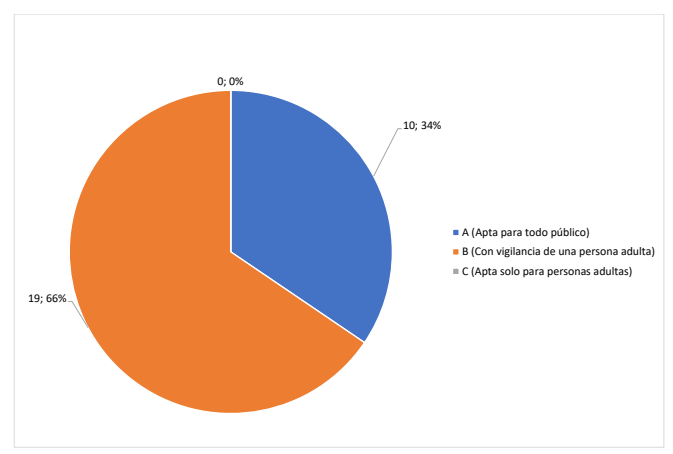

Figura 2. Tipo de contenido en medios tradicionales propios

De un total de 29 programas entre radio y TV, 19 con un porcentaje de $66 \%$ son de clasificación B (Con vigilancia de una persona adulta); 10 con un porcentaje de $34 \%$ son de clasificación A (Apta para todo público); no existe contenido con clasificación C (Apta solo para personas adultas).

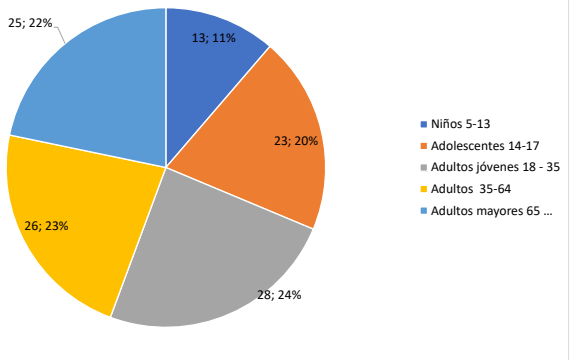

Figura 3. Público objetivo en medios tradicionales propios

De un total de 29 programas entre radio y TV, 28 con un porcentaje de $24 \%$ está dirigido a Adultos jóvenes (18 - 35) años; 26 con un porcentaje de $24 \%$ está dirigido a Adultos (35-64 años); 25 con un porcentaje de $22 \%$ está dirigido a Adultos Mayores (65 años en adelante); 23 con un porcentaje de $20 \%$ está dirigido Adolescentes (14-17) años; 13 con un porcentaje de $11 \%$ está dirigido a Niños (5-13 años).

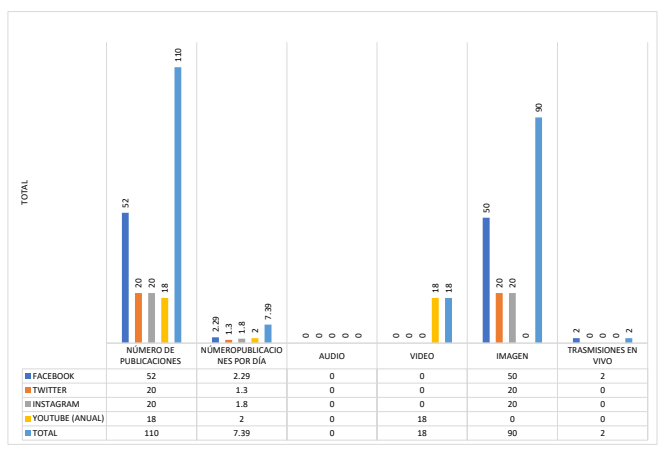

Figura 4. Medios para la publicacón de información

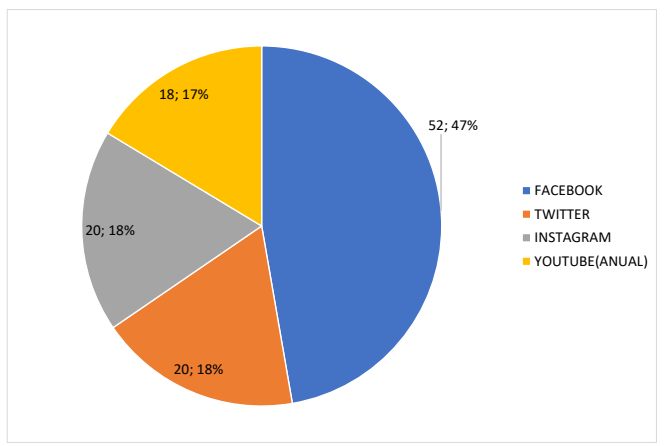

Figura 5. Medio digital más usado 
De un total de 110 publicaciones en 19 días, Facebook es la red social que más sube archivos con 52 publicaciones con un porcentaje de $47 \%$; Instagram y Twitter poseen cada una 20 publicación con un porcentaje de $18 \%$ y YouTube 18 publicaciones anuales con un porcentaje del $17 \%$.

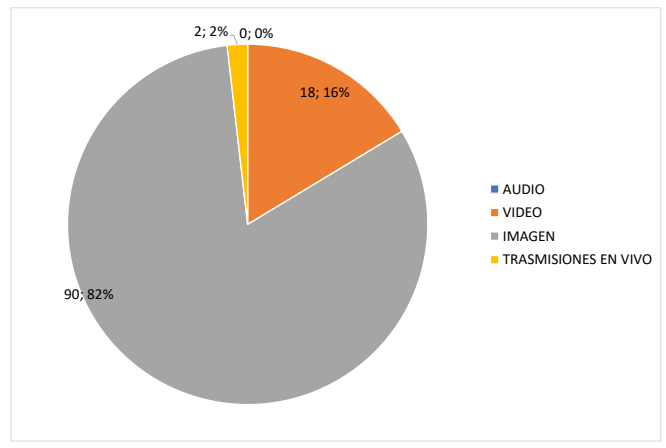

Figura 6. Tipo de archivo mas utilizados para publicaciones en medios digitales

De un total de 110 publicaciones en 19 días, el recurso mas utilizado para medios digitales es la imagen con un porcentaje de $82 \%$, seguido del video con un $16 \%$, el video representa un $2 \%$ y no existen audios.

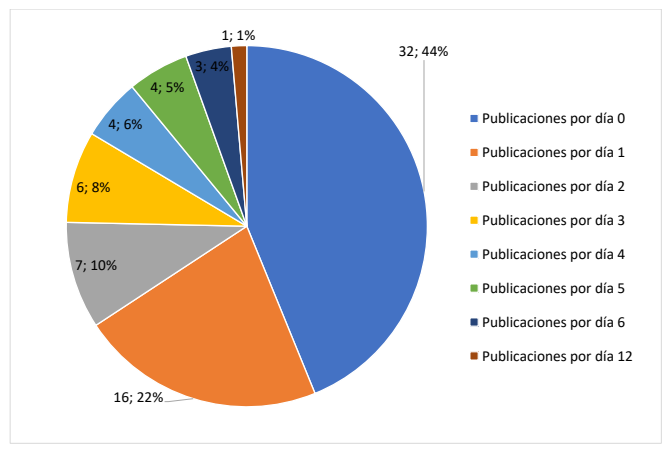

Figura 7. Promedio de publicaciones diarias

De 110 publicaciones en 19 días, 32 días con un porcentaje del $44 \%$ no subieron ningún contenido; 1 publicación por 16 días con un porcentaje $22 \%$; 2 publicaciones por 7 días con un porcentaje $10 \% ; 6$ publicaciones por 3 días con un porcentaje $4 \% ; 3$ publicaciones por 6 días con un porcentaje $8 \%$; 4 publicaciones por 4 días con un porcentaje $6 \%$; 5 publicaciones por 4 días con un porcentaje $5 \% ; 12$ publicaciones por 1 días con un porcentaje $1 \%$.

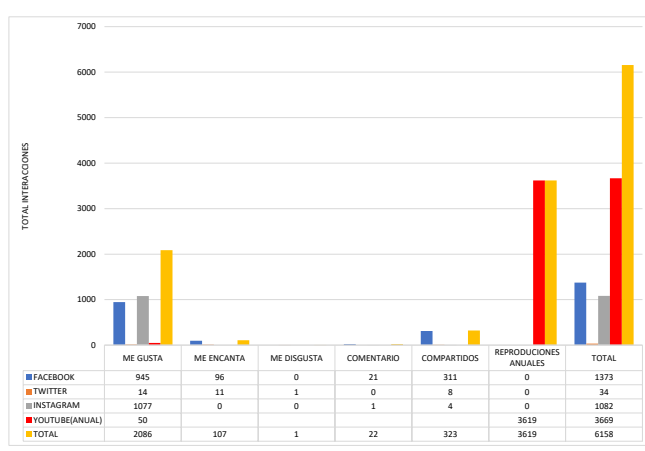

Figura 8. Resumen de interacciones

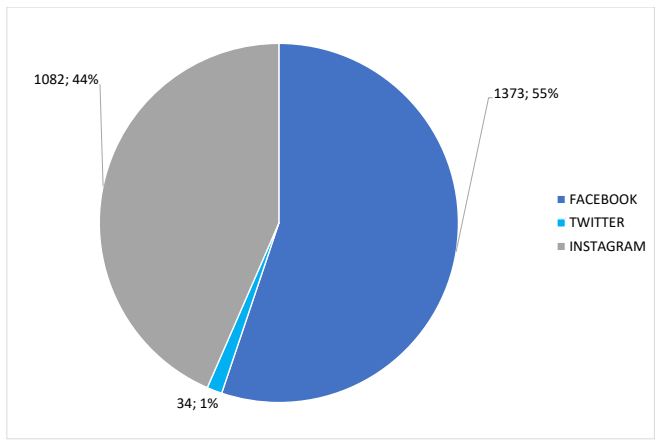

Figura 9. Medio Digital con mas interacciones

De un total de 110 publicaciones, el medio digital con mas interactividad es Facebook con 1373 que representa un $55 \%$; Instagram por su parte posee 1082 con un porcentaje del $44 \%$ de interacciones; Twitter posee 34 con un porcentaje de $1 \%$ de interacciones.

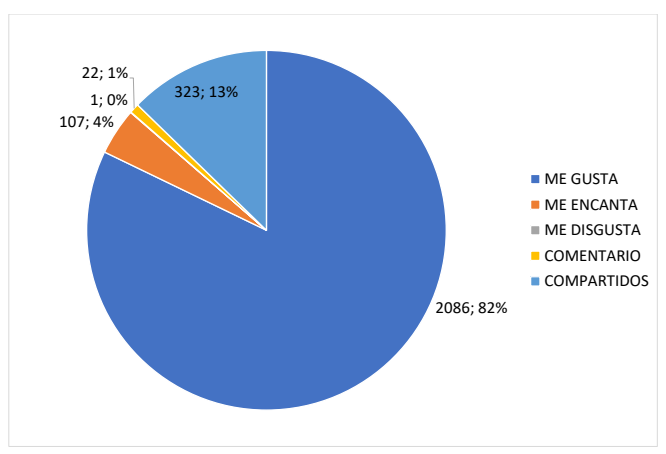

Figura 10. Resumen de interaciones en medios digitales

De un total de 110 publicaciones se obtienen: $2086 \mathrm{Me}$ Gusta con un porcentaje del 82\%; 323 Compartidos con un porcentaje del 13\%; 107 Me Encanta con un porcentaje del $4 \%$; 22 Comentarios con un porcentaje del $1 \%$ y $1 \mathrm{Me}$ Disgusta con un porcentaje del $0 \%$. 


\subsubsection{Tipo de contenido}

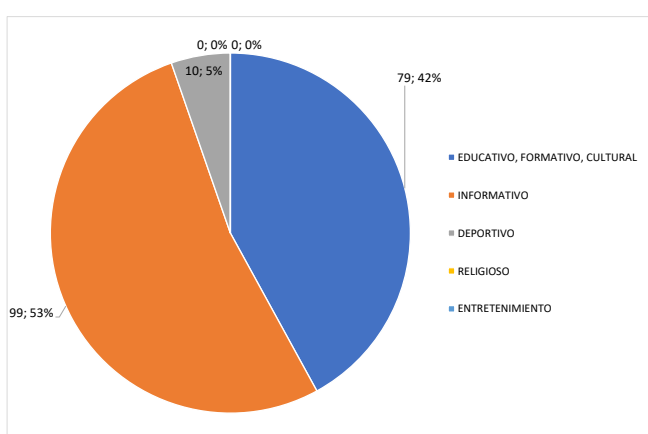

Figura 11. Tipo de información en medios digitales

99 publicaciones con un porcentaje del $53 \%$ son de carácter Informativo, 79 con un porcentaje del $42 \%$ son de carácter Educativa, Formativa, Cultural; 10 con un porcentaje del $5 \%$ es de carácter Deportivo.

\section{Conclusiones y recomendaciones}

El objetivo principal de este artículo es la de fortalecer la comunicación institucional de la Universidad Católica de Cuenca, mediante la investigación teórica y de campo.

Para demostrar si la comunicación es efectiva se investigó la existencia de los sistemas de difusión institucional, de los cuales no se encontraron registros o evidencias de su existencia dentro de la universidad, a la vez de la negación a una entrevista profunda por parte del departamento de comunicación. Por tal motivo se realizó una entrevista al exdirector de este departamento el cual confirmó que desconocía si en la actualidad dichos documentos se hayan elaborado.

Al no encontrar los sistemas de difusión institucional se procedió a realizar un análisis de audiencia y contenido a los medios de comunicación tradicionales y digitales con los que cuenta la universidad. Por el lado de los medios tradicionales esta Telecuenca y Ondas Cañaris, y el de los medios digitales están las cuentas oficiales de redes sociales como Facebook, Instagram, Twitter, YouTube y su página web oficial.

Los resultados de los medios tradicionales en cuanto a su tipo de programación es el enfoque al entretenimiento, al aspecto religioso y educativo siendo su contenido de clasificación B (Con vigilancia de una persona adulta) con un target de adolescentes, adultos jóvenes y adultos.

Al estudiar los medios digitales por 19 días se puede concluir que el medio más utilizado es Facebook con una gran diferencia ante Instagram y Twitter, utilizando en su mayoría imágenes en sus publicaciones con línea gráfica institucional casi en su totalidad. El promedio de publicaciones diarias es una; Me Gusta fue la interacción más utilizada por los usuarios; en el caso de YouTube no se pudo realizar el análisis en este tiempo ya que este medio sube contenidos esporádicamente, por lo cual se lo analizó en un tiempo de 11 meses donde con 18 videos consiguió 3619 reproducciones. Por otra parte, el tipo de contenido en estas redes sociales es de carácter informativo, educativo formativo y cultural dirigido a adolescentes, adultos jóvenes y adultos. Se pudo notar además que los contenidos se repiten en diferentes medios digitales.

Para medir el uso y aceptación de los medios de comunicación antes mencionados por parte de los estudiantes se aplicó una encuesta a una muestra de 400 estudiantes de los últimos ciclos, se seleccionó las carreras con mayor población estudiantil de varias unidades académicas. Se pudo conocer que el $91 \%$ y el $92 \%$ de los estudiantes no conocen las políticas de comunicación institucional ni las funciones de su departamento. Por otra parte, solo el $50 \%$ de los encuestados conocía los medios tradicionales como Telecuenca u Ondas Cañaris y solo 122 los había escuchado o visto alguna vez.

En cuanto a la opinión sobre medios tradicionales, el $38 \%$ de encuestados dicen que ondas Cañaris y Telecuenca es Regular.

Para los encuestados el medio digital más usado para conocer las noticias generadas por la universidad es Facebook en primer lugar, pagina web en segundo Lugar e Instagram en tercer lugar; por el lado de los medios tradicionales el $52 \%$ de los estudiantes contestaron que no lo ocupan los medios tradicionales el otro $25 \%$ ocupa Telecuenca y el $23 \%$ usa la radio Ondas Cañaris.

Utilizando adecuadamente tanto medios digitales como tradicionales se conseguirá fortalecer la comunicación institucional de la Universidad Católica de Cuenca.

\section{Referencias Bibliográficas}

Borrero-Cabal, A. (2008). La universidad. estudios sobre sus orígenes, dinámicas y tendencias: Vol. 1. historia universitaria: la universidad en europa desde sus orígenes hasta la revolución francesa. Edtitorial Pontificia Universidad Javeriana.

Castells, M. (2013). Comunicación y poder. Siglo XXI Editores México.

Castro, B. (2007). El auge de la comunicación corporativa.

CEPAL, N. (2018). Agenda 2030 y los objetivos de desarrollo sostenible: una oportunidad para américa latina y el caribe.

De la Garza Aguilar, J. (2008). Evaluación y acreditación de la educación superior en américa latina y el caribe. En La educación superior en américa latina y el caribe: diez años después de la conferencia mundial de 1998 (p. 175).

Francés, M. Á. (2005). Socialización, educación y reproducción cultural: Bordieu y bernstein. Revista interuniversitaria de formación del profesorado, 19(1), 159-174.

Fuenzalida, V. (1986). Educación para la comunicación televisiva. Ceneca. 
Martín-Barbero, J. (1998). Heredando el futuro: pensar Recibido: 30 de julio de 2019 la educación desde la comunicación. Cultura y Educación: Culture and Education(9), 17-36.

Martín-Barbero, J. (2009). Entre saberes desechables y saberes indispensables. Centro.

Martín-Barbero, J., y cols. (2001). De las políticas de comunicación a la reimaginación de la política. Nueva Sociedad, 175, 70-84.

Tünnermann, C. (2007). La universidad necesaria para el siglo xxi. Managua: Hispamer.

Tünnermann Bernheim, C. (2018). La educación superior en américa latina y el caribe: diez años después de la conferencia mundial de 1998. 
